www.nature.com/ijo

\title{
EDITORIAL
}

\section{Workshop on estimating the health burden of overweight and obesity}

International Journal of Obesity (2008) 32, S1-S3; doi:10.1038/ijo.2008.80

\section{Background}

The prevalence of overweight and obesity has reached epidemic proportions in the United States, with $32 \%$ of adults classified as obese and a troubling increase in the number of children classified as overweight as well. ${ }^{1}$ This increase in overweight and obesity comes at a substantial human and economic cost because obesity is a risk factor for chronic diseases that account for a large proportion of the US health burden. ${ }^{2}$ Costs associated with obesity have been estimated as almost $6 \%$ of the national health expenditure, accounting for approximately $16 \%$ of the gross domestic product in 2006 , and are projected to increase to $19.6 \%$ by $20166^{3,4}$

To document the magnitude of an important aspect of the health burden of overweight and obesity, the number of excess deaths resulting from these risk factors has been estimated using the population attributable fraction (PAF). ${ }^{5-7}$ The PAF is defined as the proportion of events (for example, incident cases of diseases or deaths) occurring during a given time period that can be attributed to an exposure. The PAF assumes these events were caused by the exposure and would not have occurred during that period had the exposure not occurred. Some controversy surrounds the proper use and interpretation of PAF estimates, however. ${ }^{8-11}$ To clarify the limitations and appropriate use of PAF and, more broadly, issues of causality and confounding, The Centers for Disease Control and Prevention sponsored a workshop on Estimating the Health Burden of Overweight and Obesity in May 2006. This workshop extended the efforts of an Institute of Medicine workshop, held in December 2004, ${ }^{12}$ to estimate the contributions of lifestyle-related factors to preventable death, but focused more narrowly on overweight and obesity. Experts from the United States and Canada were invited to attend a $1 \frac{1}{2}$-day workshop to discuss the methodologic limitations in explaining causal mechanisms in the pathway from overweight and obesity to relevant outcomes such as diabetes, confounding and risk modification in observational studies of these health outcomes, and in a discussion of measures of overweight and obesity, misclassification. The articles published in this supplement of the International Journal of Obesity are derived from the presentations given in the 2006 workshop.
The workshop on Estimating the Health Burden of Overweight and Obesity was held to clarify the proper use and interpretation of PAF and dealt primarily with excess mortality as an outcome. Questions of causality, confounding and misclassification were central to the discussions. The product was not intended to be a consensus on the topics discussed, but to provide a discussion by experts that could inform the design and interpretation of studies intended to measure the effects of overweight and obesity on mortality and disease.

Despite the methodologic and conceptual focus of the workshop, it is important not to lose sight of the fact that the prevalence of obesity is increasing, and it is a risk factor for diabetes, hypertension, dyslipidemia, heart disease and certain cancers. ${ }^{13}$ Even if we cannot currently calculate the exact health burden of these conditions, the numbers of people affected by overweight and obesity and their consequences deserve the attention of the public health community, which should focus on its role in ameliorating this epidemic and filling, as much as possible, the gaps in our knowledge.

\section{Causal mechanisms}

Levine $^{14}$ opened the workshop by explaining mathematically and conceptually the proper use and interpretation of the PAF. Levine ${ }^{14}$ and Hernán ${ }^{15}$ both stressed the need to specify the intervention when trying to estimate the PAF, because the consequences of reaching or maintaining a given body mass index (BMI) depend on the intervention. For example, given two populations with a mean BMI of 31 and with similar risk profiles for cardiovascular or other diseases, attaining a mean BMI of 24 by different interventions (for example, physical activity and diet vs gastric bypass surgery) will alter interpretation of the PAF depending on the intervention. Even though the BMIs are the same, intervention-related differences can directly alter morbidity and mortality as well as the risk profile of the two populations relative to each other.

Scientists and policy makers agree that evidence from observational studies and randomized controlled trials is needed to understand the causes of overweight and obesity and related health outcomes and to guide choices for interventions. Although randomized controlled trials by design seek to eliminate confounding factors, more data will probably come from observational studies because they are less expensive and labor-intensive. Hernán ${ }^{15}$ and Robins ${ }^{16}$ described 
S2

methods for dealing with the problems of unrecognized exposures and confounding variables that change over time.

Robins ${ }^{16}$ presented methods for using longitudinal epidemiologic data to estimate the impact of obesity on years of life lost or quality of years of life lost. The methods he described render observational data more comparable to randomized trials. Problems with observational data arise, in part, because of an inability to deal appropriately with covariates that change with time or that cannot be classified with certainty as confounders or as intermediates in a causal pathway. For example, in the relationship between obesity and death, should blood pressure, cholesterol and diabetes be treated as confounders or intermediate variables? Robins ${ }^{16}$ proposed the use of the G-estimation of a structural nested failure time model, a method that, in observational studies, has each person serving as his or her own control, thereby minimizing confounding variables.

\section{Confounding and risk modification}

Flanders, ${ }^{17}$ Cooper ${ }^{18}$ and Durazo-Arvizu ${ }^{19}$ discussed the problem of reverse causality, in which an observed cause-and-effect relationship is the opposite of what might be assumed from the data. Although investigators have at times concluded that having a normal BMI (cause) increases risk for illness or death (effect), ${ }^{5}$ reverse causality would suggest that people have a normal BMI because they are sick (cause) and losing weight (effect).

Some investigators recommend excluding groups that may cause reverse causality from the data analysis. Exclusions at baseline might include people with chronic disease, those older than 70 years, smokers or elimination of the first several years of follow-up. ${ }^{20,21}$ These investigators argue that the cumulative effects of obesity on mortality may not be apparent when calculating PAF for someone who dies at age 70 with a normal BMI but who was obese earlier in life. ${ }^{21}$ Others argue that exclusion of groups is not advisable for several reasons, including loss of the sample's representativeness. ${ }^{17-19,22}$

Flanders ${ }^{17}$ stressed the importance of understanding causal relationships rather than simply looking at observed mortality ratios. He encouraged the use of sensitivity analyses and G-estimation, as well as consideration of animal models to better understand biological causality mechanisms. Cooper ${ }^{18}$ cautioned that data exclusion is always risky because it can produce spurious results due to chance. Durazo-Arvizu ${ }^{19}$ analyzed data sets from multiple large studies to show that excluding smokers does not lead to different conclusions any more often than would be expected by chance alone, thus arguing that reverse causality may not be as significant a problem as some have suggested.

\section{Misclassification}

Body mass index is the most commonly used measure of adiposity. Most current guidelines use this measure to classify people as underweight, normal, overweight or obese.
The correlation of this measure with health outcomes compared to other measures of adiposity and the problem of bias introduced by self-reported weight and height for calculation of BMI were discussed.

Rothman $^{23}$ discussed the possibility of bias introduced by self-reported weight and height as well as the consequences of errors in the measurement of obesity using BMI. He pointed out that the potential for differential misclassification is more problematic for case-control and cross-sectional studies than prospective cohort studies. Furthermore, differential misclassification can produce bias toward or away from the null.

Stevens $^{24}$ discussed the feasibility of using alternative measures of adiposity such as circumferences, skin folds or dual-energy X-ray absorptiometry to obtain stronger associations with adverse health outcomes. Although BMI doesn't distinguish muscle from adipose tissue or assess regional adiposity, it is the most commonly-used measure of adiposity. Because measures of adiposity are reasonably well-correlated, one should weigh the trade-offs between precision and accuracy versus cost and practicality when selecting a measure. The measure of adiposity must correlate with outcomes, but must also be easily interpretable in the public health setting.

\section{Conclusion}

This workshop focused on estimating the health burden of obesity using PAF and methods to minimize bias in observational studies. Use of PAF implies a causal relationship between obesity and health outcomes, and its magnitude depends on the intervention used. One of the most significant challenges in public health is documenting effective interventions for evidence-based practice.

The workshop did not address the equally complex issues that characterize the debate about how to respond to the obesity epidemic in the absence of definitive evidence to support specific interventions. The results of interventional trials have been inconsistent for many reasons, including formidable methodological limitations and lack of comparability. ${ }^{25,26}$ A preliminary review of school-based interventions by the Task Force on Community Preventive Services concluded that evidence is insufficient to support combined school-based nutrition and physical activity interventions to control childhood obesity. ${ }^{26}$ Nonetheless, the need to act is urgent, and some evidence supports the use of such schoolbased interventions. ${ }^{27}$ The Task Force did find sufficient evidence to recommend worksite programs to control obesity, and several promising school-based interventions to prevent or reduce obesity have been published. ${ }^{26}$ Furthermore, The Centers for Disease Control and Prevention has supported a population-based clinical trial providing evidence that reducing or controlling overweight and obesity by diet and exercise in the setting of individual counseling can delay onset of type 2 diabetes. ${ }^{28}$ This study adds support for adaptation of these methods for population-based interventions. 
The challenge of insufficient evidence in the face of an urgent need led the authors of the Institute of Medicine report, Preventing Childhood Obesity, to emphasize the need to act on the best available evidence rather than to wait for the best possible evidence. ${ }^{29}$ As investigators use methods such as those presented here to obtain evidence from observational studies and controlled trials, many in the public health arena also look for such information via 'practice-based evidence' from ongoing participatory research that, advantageously, incorporates multiple, real-world influences in simulating complex reality. ${ }^{30}$

The authors express their deep appreciation to Dr Harvey Fineberg, President of the Institute of Medicine, whose leadership made this workshop possible and to Carol Cook whose tireless efforts made this supplement possible.

\section{Conflict of interest}

Neither author declared any financial interests.

\section{Acknowledgements}

The opinions in this report are those of the authors and do not necessarily represent the views of the Centers for Disease Control and Prevention.

KK Steinberg and WH Dietz

Coordinating Center for Health Promotion, Centers for Disease Control and Prevention, Atlanta, GA, USA E-mail:kks1@cdc.gov

\section{References}

1 Ogden CL, Carroll MD, Curtin LR, McDowell MA, Tabak CJ, Flegal KM. Prevalence of overweight and obesity in the United States, 1999-2004. JAMA 2006; 295: 1549-1555.

2 Mokdad AH, Ford ES, Bowman BA, Dietz WH, Vinicor F, Bales VS et al. Prevalence of obesity, diabetes and obesity-related health risk factors, 2001. JAMA 2003; 289: 76-79.

3 Wolf AM, Colditz GA. Current estimates of the economic cost of obesity in the United States. Obes Res 1998; 6: 97-106.

4 DoBias M, Lubell J, Becker C. CMS: spending growth slows. However, experts say GDP projections alarming. Mod Healthc 2007; 37: 8-9, 12, National Health Care expenditures Projections: 2006-2016, 'CMS Office of the Actuary' http://www.cms.hhs.gov/ NationalHealthExpendData/downloads/proj2006.pdf.

5 Flegal KM, Graubard BI, Williamson DF, Gail MH. Excess deaths associated with underweight, overweight, and obesity. JAMA 2005; 293: 1861.

6 Mokdad AH, Marks JS, Stroup DF, Gerberding JL. Actual causes of death in the United States, 2000. JAMA 2004; 291: 1238-1245.

7 Allison DB, Fontaine KR, Manson JE, Stevens J, VanItallie TB. Annual deaths attributable to obesity in the United States. JAMA 1999; 282: 1530-1538.

8 Greenberg J. Underweight, overweight, obesity, and excess deaths. JAMA 2005; 294: 552.

9 Ding EL. Underweight, overweight, obesity, and excess deaths. IAMA 2005; 294: 552
10 Willett WC, Hu FB, Colditz GA, Manson JE. Underweight, overweight, obesity, and excess deaths. JAMA 2005; 294: 551.

11 Flegal KM, Graubard BI, Gail MH, Williamson DF. Underweight, overweight, obesity, and excess deaths. Author reply. JAMA 2005; 294: 552-553.

12 Institute of Medicine. Estimating the Contribution of LifestyleRelated Factors to Preventable Deaths: A Workshop Summary. National Academies Press: Washington DC, 2005, http://www.iom. edu/CMS/3793/24066.aspx.

13 National Heart, Lung, and Blood Institute in cooperation with the National Institute of Diabetes and Digestive and Kidney Diseases. Clinical Guidelines on the Identification, Evaluation, and Treatment of Overweight and Obesity in Adults. The Evidence Report. National Institutes of Health: Bethesda, MD, 1998.

14 Levine BJ. The other causality question: estimating attributable fractions for obesity as a cause of mortality. Int J Obes 2008; 32(Suppl 3): S4-S7.

15 Hernán MA, Taubman SL. Does obesity shorten life? The importance of well-defined interventions to answer causal questions. Int J Obes 2008; 32(Suppl 3): S8-S14.

16 Robins JM. Causal models for estimating the effects of weight gain on mortality. Int J Obes 2008; 32(Suppl 3): S15-S41.

17 Flanders WD, Augestad LB. Adjusting for reverse causality in the relationship between obesity and mortality. Int J Obes 2008; 32(Suppl 3): S42-S46.

18 Cooper RS. Which factors confound or modify the relationship between body weight and mortality? Int J Obes 2008; 32(Suppl 3): S47-S51.

19 Durazo-Arvizu RA, Cooper RS. Issues related to modeling the body mass index-mortality association: the shape of the association and the effects of smoking status. Int J Obes 2008; 32(Suppl 3): S52-S55.

$20 \mathrm{Hu}$ FB, Willett WC, Stampfer MJ, Spiegelman D, Colditz GA. Calculating deaths attributable to obesity. Am J Public Health 2005; 95: 932.

21 Manson JE, Bassuk SS, Hu FB, Stampfer MJ, Colditz GA, Willett WC. Estimating the number of deaths due to obesity: can the divergent findings be reconciled? J Womens Health 2007; 16: 168-176.

22 Flegal KM, Graubard BI, Williamson DF, Gail MH. Impact of smoking and preexisting illness on estimates of the fractions of deaths associated with underweight, overweight, and obesity in the US population. Am J Epidemiol 2007; 166: 975-982.

23 Rothman KJ. BMI-related errors in the measurement of obesity. Int J Obes 2008; 32(Suppl 3): S56-S59.

24 Stevens J, McClain JE, Truesdale KP. Selection of measures in epidemiologic studies of the consequences of obesity. Int $J$ Obes 2008; 32(Suppl 3): S60-S66.

25 Thomas $H$. Obesity prevention programs for children and youth: why are their results so modest? Health Educ Res 2006; 21: 783-795.

26 Katz DL, O'Connell M, Yeh M-C, Nawaz H, Njike V, Anderson LM et al. Task force on community preventive services. Public health strategies for preventing and controlling overweight and obesity in the school and worksite settings: a report on recommendations of the Task Force on Community Preventive Services. MMWR Recomm Rep 2005; 54 (RR10): 1-12.

27 Franks A, Kelder SH, Dino GA, Horn KA, Gortmaker SL, Wiecha JL et al. School-based programs: lessons learned from $\mathrm{CATCH}$, planet health, and not-on-tobacco. Prev Chronic Dis 2007; 4: A33.

28 Knowler WC, Barrett-Conner E, Fowler SE, Hamman RF, Lachin $\mathrm{JM}$, Walker EA et al. Diabetes prevention program research group. Reduction in the incidence of type 2 diabetes with lifestyle intervention or metformin. N Engl J Med 2002; 346: 393-403.

29 Koplan JP, Liverman CT, Kraak VA, (eds), Committee on Prevention of Obesity in Children and Youth. Preventing Childhood Obesity: Health in the Balance. National Academies Press: Washington DC, 2005

30 Green LW. Public health asks of systems science: to advance our evidence-based practice, can you help us get more practice-based evidence? Am J Public Health 2006; 96: 406-413. 